\title{
Analisis Perceived Organizational Support, Quality Culture, dan Kepuasan Kerja sebagai Second-Order Factor terhadap Turnover Intention Karyawan Generasi Y di ATC (Air Traffic Control)
}

\author{
Honorata Ratnawati Dwi Putranti \\ Suparmi \\ Sri Suprapti \\ Manajemen, Universitas 17 Agustus 1945 Semarang, Indonesia \\ Korespondensi penulis: honorata-ratnawati@untagsmg.ac.id
}

\begin{abstract}
The meeting between generations is now starting to be felt in all organizations, and new things in Human Resources management. Differences in character, motivation, and characteristics in each create a contribution to the human resource management of an organization/company. This study aims to analyze Y-generation employees at ATC (Air Traffic Control) by examining the relationship between variables, perceived organizational support, job satisfaction, quality culture, and intention to move. The research object is ATC employees of seven airports in Indonesia with a total population of 620. The sample of this study is Y-generation of the ATC employees, which is as many as 225, with a purposive sampling method. Research data processing using AMOS version 24 with job satisfaction as the second-order (internal and external dimensions). The results showed that perceived organizational support and quality culture affected turnover intention which was moderated by job satisfaction. This research is expected to contribute to the understanding of job satisfaction which consists of external and internal dimensions that affect Y-generation in turnover intention.
\end{abstract}

Keywords: ATC (Air Traffic Control); Job satisfaction; Quality culture; Second-order factor; Turnover Intention.

\begin{abstract}
Abstrak. Saat ini, pertemuan antargenerasi mulai banyak dirasakan di semua organisasi. Kondisi tersebut memunculkan hal-hal baru di dalam pengelolaan sumber daya manusia (SDM). Perbedaan karakter, motivasi, dan ciri-ciri khas pada setiap generasi memberikan kontribusi dalam pengelolaan SDM maupun organisasi/perusahaan. Penelitian ini bertujuan untuk menganalisis karyawan generasi Y di ATC (Air Traffic Control) dengan menguji hubungan antarvariabel, yaitu perceived organizational support (POS), job satisfaction, quality culture, dan turnover intention. Obyek penelitian adalah karyawan tujuh bandar
\end{abstract}


udara (bandara) di Indonesia dengan populasi sebanyak 620 orang karyawan. Sampel yang digunakan dalam penelitian ini adalah karyawan ATC dari generasi Y di tujuh bandara tersebut sebanyak 225 orang dengan metode purposive sampling. Pengolahan data dalam penelitian ini menggunakan bantuan Analysis of Moment Structure (AMOS) versi 24 dengan job satisfaction sebagai second-order factor (dimensi internal dan eksternal). Hasil penelitian ini menunjukkan bahwa perceived organizational support dan quality culture berpengaruh terhadap turnover intention yang dimoderasi oleh job satisfaction. Hasil penelitian ini memberikan kontribusi pemahaman terhadap job satisfaction yang terdiri atas dimensi eksternal dan internal yang dapat mempengaruhi generasi Y dalam turnover intention.

Kata kunci: ATC (Air Traffic Control); Kepuasan kerja; Kualitas budaya; Second-order factor; Turnover intention.

Article Info:

Received: November 27, 2020

Accepted: March 26, 2021

Available online: April 14, 2021

DOI: http://dx.doi.org/10.30588/jmp.v10i2.765

\section{LATAR BELAKANG}

Saat ini, perusahaan adalah tempat kerja sebagai tempat bertemunya tenaga kerja multi generasi yang ditandai oleh berbagai mentalitas dan prioritas generasi. Generasi Y dikenal sebagai generasi milenial, yaitu mereka yang lahir periode tahun 1980-2004 (Kam, Lim, Al-Obaidi, \& Lim, 2018). Sekarang ini, sebagian besar generasi X akan pensiun dan banyak generasi Y yang masuk ke dunia kerja. Generasi Y adalah mereka yang memiliki karakteristik terlalu percaya diri, berpendidikan lebih baik, dan lebih mengerti teknologi daripada generasi sebelumnya (Nurhasan, 2017). Mengelola karyawan generasi Y di tempat kerja menimbulkan tantangan nyata bagi manajer sumber daya manusia (SDM). Dengan bergesernya tenaga kerja muda dari generasi X ke generasi $\mathrm{Y}$, perusahaan perlu mengubah kebijakan mereka. Saat ini, tiga klasifikasi generasi SDM yang banyak digunakan, yaitu generasi Baby Boomers, Generasi X, dan Generasi Y (Mcguire, By, \& Hutchings, 2007) dan menekankan pentingnya mengelola interaksi antargenerasi pekerja.

Generasi Y telah menjadi bagian integral dari budaya dunia (Mcguire et al., 2007). Saat ini, Indonesia mengalami permasalahan yang sama dengan masuknya generasi Y dalam dunia industri. Situasi ini dapat berbeda dengan beberapa wilayah atau negara lain, karena karakteristik suatu wilayah atau negara berbeda satu sama lain (da Silva, Dutra, Veloso, Fischer, \& Trevisaqn, 2015). Di Indonesia, generasi milenial menjadi generasi yang sangat penting dalam upaya memajukan bangsa karena jumlahnya yang sangat besar. Dari hasil sensus penduduk yang digelar Badan Pusat Statistik (BPS), jumlah penduduk Indonesia hingga tahun 2020 didominasi oleh generasi $\mathrm{Z}$ dan generasi milenial. Generasi Z adalah penduduk yang lahir pada periode tahun 1997-2012, sedangkan generasi milenial adalah mereka yang lahir pada periode tahun 1981-1996. Dari hasil survei sepanjang Februari-September 2020, jumlah penduduk generasi $\mathrm{Z}$ mencapai 75,49 juta jiwa atau 
setara dengan 27,94 persen dari total populasi berjumlah 270,2 juta jiwa. Sementara, generasi milenial mencapai 69,90 juta jiwa atau 25,87 persen (Antara, 2021).

Usia pekerja berpengaruh pada turnover intention (TI) dan tergantung pada jenis organisasi maupun masa kerja, serta keterlibatannya dalam perusahaan (Emiroğlu, Akova, \& Tanrıverdi, 2015), Usia merupakan faktor yang mempengaruhi TI, sehingga karyawan muda cenderung berkeinginan untuk meninggalkan perusahaan, karena ia ingin mendapatkan pekerjaan yang lebih baik (Prawitasari, 2016). Menurut Kismono, Rosari, dan Suprihanto (2013), usia dan TI memiliki hubungan negatif, yaitu semakin bertambahnya usia maka TI cenderung semakin menurun karena pekerja sudah beradaptasi dengan lingkungan di sekitarnya. Orang dengan usia lebih tua memiliki TI yang lebih rendah, karena fakta menunjukkan bahwa mereka tidak memiliki pemikiran dan harapan yang sama dibandingkan dengan mereka yang lebih muda usia (Emiroğlu et al., 2015). Dengan demikian, TI berbeda berdasarkan usia dan tidak ada perbedaan TI pada orang-orang dengan kelompok usia yang sama (Choong, Keh, Tan, \& Tan, 2013).

Berbagai hasil penelitian yang berbeda telah dilakukan sebelumnya. Beberapa penelitian tentang turnover intention lebih memfokuskan pada jenjang usia yang beragam tanpa membedakan usia, seperti pada penelitian Asmara (2017) dan Aydogdu dan Asikgil (2011). Penelitian lain juga memperlihatkan bahwa perbedaan latar belakang organisasi juga menyebabkan hasil beragam, seperti penelitian di sektor manufaktur yang menyebabkan gangguan pada biaya apabila terlalu banyak mengalami TI (Skelton, Nattress, \& Dwyer, 2020). Hal itu telah membuktikan bahwa latar belakang karyawan yang berbeda dapat mengakibatkan tingkat turnover intention yang berbeda pula. Oleh karena itu, penelitian ini untuk mengetahui lebih lanjut sejauh mana asumsi yang diusulkan valid dalam kasus obyek perusahaan milik pemerintah di bidang transportasi udara, khususnya karyawan ATC.

ATC (Air Traffic Control) atau pengendali lalu lintas udara secara luas diakui sebagai kelompok kerja yang harus menghadapi pekerjaan yang sangat menuntut serangkaian tugas yang kompleks, membutuhkan pengetahuan dan keahlian yang tinggi, tanggung jawab besar, yang tidak hanya berkaitan dengan risiko hidup penumpang, tetapi juga aktivitas penerbangan lainnya (Budiman, Pujangkoro, \& Anizar, 2013). Kelancaran lalu lintas pesawat udara sangat tergantung pada komunikasi dan informasi yang diberikan oleh petugas ATC dan pilot pesawat. Kesalahan di dalam komunikasi antara keduanya dapat menyebabkan terjadinya kecelakaan atau masalah-masalah yang membahayakan penerbangan. Pada intinya, layanan lalu lintas udara dilaksanakan agar operasi penerbangan dapat berjalan aman, lancar, teratur, dan efisien. Semakin tinggi frekuensi penerbangan yang melintas atau pun mendarat di sebuah bandar udara, maka hal itu semakin membuat tegang pegawai ATC. Kondisi inilah yang menyebabkan perlunya perhatian terhadap karyawan ATC untuk selalu bekerja prima, sehingga mereka dapat merasakan kepuasan dalam pekerjaannya dan memberikan kontribusi pada komitmen organisasi dengan lebih baik. Data jumlah karyawan yang bekerja di ATC tujuh bandara menurut DNP (Direktorat Navigasi Penerbangan, 2020) ditunjukkan pada Tabel 1.

Data dari tujuh bandara menunjukkan bahwa jumlah generasi Y sebanyak 300 orang (Tabel 1). Artinya, dari jumlah karyawan generasi Y tersebut, lebih dari 50\%nya masih memiliki jenjang karir yang panjang dan kesempatan yang lebih luas, sehingga mereka 
perlu menjadi perhatian perusahaan untuk menjaga potensi dan jenjang karir yang panjang tersebut. Karyawan yang memiliki kesempatan baik dapat menjadi stress, apabila ia tidak mendapatkan dukungan dari organisasi dan berpotensi memunculkan turnover intention (Ratnasari \& Prasetyo, 2018). Turnover interntion (TI) dapat terjadi di berbagai jenis perusahaan, seperti perusahaan manufaktur, bank, perusahaan telekomunikasi, rumah sakit, dan perusahaan perhotelan (Putranti, Lelono, \& Suparmi, 2019). Perbedaan situasi dan kasus dalam setiap organisasi akan memunculkan perbedaan hasil. Tingginya tingkat turnover intention mengakibatkan terganggunya operasi perusahaan, produktivitas, dapat berdampak pada waktu dan biaya, serta waktu yang hilang untuk merekrut staf baru. TI berkaitan dengan hasil tes individu tentang kesinambungan hubungan dengan organisasi. Hal tersebut sangat penting, karena TI adalah prediksi kuat seseorang meninggalkan perusahaan (Ningsih \& Arsanti, 2014; Emiroğlu et al., 2015). Mempertahankan karyawan yang berpotensi sangat penting bagi perusahaan, sedangkan efektifitas, efisiensi, dan dukungan dari organisasi atau perceived organizational support (POS) merupakan faktor penting bagi manajer dan karyawan (Jayasundera, Jayakody, \& Jayawardana, 2017).

\begin{tabular}{clc}
\multicolumn{2}{c}{ Tabel 1. Jumlah Karyawan ATC (Air Traffic Control) } & Tujuh Bandara di Indonesia \\
\hline No & \multicolumn{1}{c}{ Nama Bandara } & $\begin{array}{c}\text { Jumlah Karyawan } \\
\text { ATC (orang) }\end{array}$ \\
\hline 1 & Bandar Udara Internasional Yogyakarta, Kulon Progo, Yogyakarta & 25 \\
\hline 2 & Bandar Udara Sultan Muhammad Salahudin, Bima, Nusa Tenggara Barat & 8 \\
\hline 3 & Bandar Udara Internasional Soekarno-Hatta, Cengkareng, Jakarta & 385 \\
\hline 4 & Bandar Udara Internasional Hang Nadim, Batam, Kepulauan Riau & 35 \\
\hline 5 & $\begin{array}{l}\text { Bandar Udara Sultan Mahmud Badaruddin II, Palembang, Sumatera } \\
\text { Selatan }\end{array}$ & 54 \\
\hline 6 & Bandar Udara Internasional Ahmad Yani, Semarang, Jawa Tengah & 54 \\
\hline 7 & Bandar Udara Internasional Juanda, Surabaya, Jawa Timur & 59 \\
\hline & Jumlah seluruh karyawan ATC & 620 \\
\hline & Jumlah karyawan generasi Y & 300 \\
\hline
\end{tabular}

Sumber: Direktorat Navigasi Penerbangan (2020).

POS atau dukungan organisasi sangat relevan dalam memberikan kontribusi terhadap kualitas hidup yang lebih baik pada organisasi, serta pengaruhnya terhadap kesehatan fisik dan mental (Cullen, Edwards, Casper, \& Gue, 2014). Dukungan organisasi dapat dipahami melalui aspek psikologis. Artinya, dukungan organisasi disebut sebagai bantuan yang diberikan oleh organisasi dan dapat mempengaruhi keselamatan karyawan. Dukungan organisasi tersebut akan mempromosikan kesejahteraan dan kepuasan karyawan, meningkatkan kualitas hidup di tempat kerja, dan persepsi terhadap POS. Beberapa penelitian sebelumnya menekankan pentingnya POS dan pengaruh dukungan yang diberikan oleh manajer pada motivasi karyawan generasi Y. Sebuah penelitian menyatakan bahwa dukungan organisasi dan dukungan manajemen bersifat independen, tetapi keduanya dapat bekerja sama dengan baik untuk menentukan kepuasan karyawan (Meier, Austin, \& Crocker, 2010). 
Hubungan antara pemimpin dan pengikut menjadi faktor penting dalam hubungan antara motivasi karyawan dan manajer (García-Morales, Lloréns-Montes, \& Verdú-Jover, 2008). Faktor-faktor yang meliputi beban emosional yang kuat, tekanan untuk mencapai tujuan, negosiasi, konfrontasi, dan perubahan merupakan fenomena sehari-hari yang dapat menghasilkan masalah psikologis, seperti stres, depresi, dan kelelahan emosional yang secara langsung dapat mempengaruhi karyawan dan organisasi (Retnoningsih, Sunuharjo, \& Ruhana, 2016). Secara psikologis, dukungan organisasi tidak hanya terfokus pada ukuran finansial, tetapi juga dukungan non-finansial yang dapat diberikan, seperti pujian yang dapat menimbulkan rasa diterima. Pada dasarnya, manusia menyukai perlakuan yang sebanding dan adil, serta organisasi yang tidak berpihak (Dewi \& Dewi, 2018). POS di dukung oleh budaya organisasi yang diharapkan akan meningkatkan quality culture yang baik dalam meningkatkan kinerja pegawai (Ehlers, 2009). Quality culture sebagai bagian dari budaya organisasi tampaknya menjadi lebih penting dan masih ada kekurangan mendasar penelitian dibidang ini. Budaya kualitas memiliki bagian yang berwujud dan tidak berwujud, atau terlihat dan tidak terlihat. Sebuah budaya kualitas dapat dikembangkan lebih lanjut dengan baik, apabila berwujud, yaitu elemen struktural, seperti mekanisme manajemen mutu, alat, dan instrumen berkembang secara paralel dengan elemen tak berwujud, seperti komitmen, nilai, ritual, dan simbol (Ehlers, 2009). Budaya dan koherensi budaya dalam organisasi-organisasi menjadi kualitas penting dalam kesuksesan suatu organisasi. aspek organisasi ini telah menjadi sangat penting dan menarik untuk mengukur kemampuannya untuk berinovasi dan beradaptasi dengan perubahan budaya dan bagaimana hal ini mempengaruhi kinerjanya (Maamari \& Saheb, 2018).

Perbedaan dalam pendekatan dan sikap untuk bekerja dapat menyebabkan konflik antargenerasi, misalnya karyawan muda lebih berjiwa wirausaha dan melek teknologi, tetapi kurang bijaksana dibandingkan pekerja yang lebih tua. Organisasi harus berupaya mengoptimalkan talenta semua kelompok umur, mendidik dan mengembangkan karyawan untuk memanfaatkan keragaman yang ada dalam rangka keuntungan individu dan organisasi, dan mengoptimalkan keanekaragaman generasi. Bukti penelitian menunjukkan bahwa kegagalan untuk mengakui dan menyesuaikan perbedaan generasi dapat mempengaruhi produktivitas, inovasi, dan kewarganegaraan karyawan (Mcguire et al., 2007). Identitas individu dan kelompok dalam organisasi penting untuk menghasilkan hubungan sosial yang mampu memberikan motivasi lebih tinggi. Lingkungan internal perusahaan dipandang penting bagi kelangsungan hidup yang lebih sukses. Kondisi ini sesuai dengan teori pertukaran sosial (social exchange theory) yang menggambarkan berbagai perilaku yang terjadi di sepanjang kehidupan sosial seseorang yang berhubungan dengan hubungan emosional yang kuat sehingga karyawan akan berupaya mengembangkan tingkat dukungan organisasi atau pun pemimpin mereka (Cheung \& Wu, 2012). Kondisi ekonomi dan lingkungan yang kompetitif telah memaksa organisasi untuk berkonsentrasi pada peningkatan kinerja karyawan. Lingkungan kerja merupakan kombinasi faktor (dukungan sosial, kondisi kerja fisik, karakteristik pekerjaan, pelatihan dan pengembangan, dan proses komunikasi) yang mempengaruhi pekerjaan. Dukungan sosial diartikan sebagai bantuan yang diterima individu dari rekan kerja, penyelia, dan kolega untuk melakukan pekerjaannya secara efektif (Malik, Ahmad, Gomez, \& Ali, 2011). Dari uraian tersebut, penelitian ini bertujuan untuk mengetahui pengaruh persepsi dukungan organisasi (POS), quality culture, 
dan kepuasan kerja terhadap turnover intention (TI) karyawan generasi Y dengan kepuasan kerja sebagai variabel intervening.

\section{KAJIAN TEORITIS}

\section{Generational Theory}

Individu yang lahir antara tahun 1981 sampai dengan 2001 dianggap sebagai bagian dari generasi Y (Nurhasan, 2017). Bagi generasi Y, pekerjaan lebih dari sekadar sumber penghasilan, karena dapat dimotivasi oleh tantangan. Tidak ada konsensus di antara penulis tentang rentang waktu yang menentukan awal dan akhir suatu generasi. Tanggal lahir bukan satu-satunya unsur yang dapat mengelompokkan orang-orang pada generasi yang sama (Pauli, Godinho-Bitencourt, \& Costenaro-Maciel, 2019). Perilaku generasi Y telah menjadi sumber tantangan besar bagi perusahaan, seperti memahami lingkungan kerjanya. Generasi Y sangat menghargai perusahaan yang berkelanjutan bersifat fleksibel dan dinamis, serta memungkinkan mereka berinteraksi secara pribadi dan profesional yang positif antara kolega dan pemimpin dalam lingkungan yang ramah (da Silva et al., 2016). Hubungan antara pemimpin dan bawahan pada generasi ini pantas untuk dinilai secara menyeluruh. Kenyataan ini membuat motivasi dan kepuasan kerja menjadi tantangan bagi perusahaan dan membutuhkan pendekatan baru dalam kepemimpinan organisasi. Hubungan harmonis antara karyawan dan perusahaan akan menurunkan keinginan karyawan untuk meninggalkan perusahaan (Prawitasari, 2016). Martins dan Martins (2014) menyarankan organisasi untuk mengelompokkan dan membandingkan generasi di tempat kerja dan klasifikasi usia secara praktis dapat digunakan. Dengan demikian, generasi di tempat kerja saat ini diklasifikasikan sebagai Gen Y (usia 36 tahun ke bawah), Gen X (usia 37-50 tahun), dan Baby Boomers (usia 51-69 tahun).

\section{Turnover Intention (TI)}

TI diartikan sebagai suatu niat pekerja yang secara sadar dan sengaja berkeinginan untuk meninggalkan organisasinya. TI terdiri atas dua kategori, yaitu turnover sukarela dan turnover tidak sukarela. Dampak dari pergantian karyawan secara sukarela maupun yang disengaja berdampak besar bagi organisasi (Emiroğlu et al., 2015). Penyebab yang paling mungkin dari pergantian paksa adalah pengurangan biaya dan restrukturisasi organisasi. TI juga dapat menyebabkan pemborosan di bidang manajemen dan demoralisasi karyawan lain. Berbagai macam faktor penyebab TI, seperti bidang demografi. Tiga tipe dasar karakteristik demografi, yaitu jenis kelamin, usia, dan tingkat pendapatan (Choong et al., 2013). Penyebab lain terjadinya perputaran karyawan adalah faktor yang berhubungan dengan pekerjaan (kepuasan kerja, gaji, kinerja, dan komitmen organisasi), faktor individu (usia, pendidikan, jenis kelamin, dan masa kerja), dan faktor eksternal (tingkat pengangguran, persepsi pekerjaan, tingkat kehadiran, dan serikat pekerja) (Dawley, Houghton, \& Bucklew, 2010). Beberapa penelitian yang ada beranggapan bahwa TI tertinggi berasal dari generasi Y dibandingkan dengan generasi Baby Boomers dan Gen X, karyawan Gen Y lebih banyak menuntut di tempat kerja sambil menunjukkan orientasi tujuan, dorongan, dan optimism, sedangkan generasi di atasnya lebih merasa bahwa mereka sudah menemukan kenyamanan 
atau merasa memiliki keterbatasan kemampuan (Prawitasari 2016; Jayasundera et al., 2017).

\section{Perceived Organizational Support (POS) dan Turnover Intention (TI)}

POS dapat berdampak pada peningkatan komitmen, kepuasan kerja dan emosi positif, keterlibatan kerja karyawan, performa kerja, keinginan untuk menetap dalam organisasi dan menurunkan ketegangan dalam bekerja, serta menurunkan tingkat stres, sehingga mereka dapat meningkatkan produktivitas organisasi (Rhoades \& Eisenberger, 2002). Tingginya tingkat POS dapat menurunkan TI. Artinya, TI karyawan menurun ketika mereka berpersepsi bahwa organisasi peduli terhadap mereka, menghargai kontribusi mereka, serta memberikan rasa hormat dan dukungan kepada mereka (Afsar \& Badir, 2017), sehingga muncul keinginan di dalam diri karyawan untuk tidak berpindah pekerjaan ke tempat lain. Karyawan yang memiliki tingkat keterikatan kerja yang rendah akan mengalami perasaan negatif dan merasa tidak bahagia di tempat kerja, sehingga hal itu dapat mempengaruhi rekan kerjanya melalui emosi negatif dan cenderung mengalami kelelahan secara emosi (Bano, Ramzan, Anjum, \& Dapeng, 2017). Lebih lanjut, kondisi tersebut juga dapat memicu karyawan kurang inovatif dan kreatif, serta cenderung tidak ingin berbagi ide barunya dengan rekan kerjanya. Selain itu, karyawan juga cenderung merasa tidak puas, tidak berkomitmen, dan memiliki intensi untuk meninggalkan organisasi (Claudia, 2018). POS dapat membangun kepercayaan antara karyawan dan perusahaan. Komunikasi yang terbangun dengan baik akan meningkatkan komitmen karyawan kepada perusahaan. Dukungan organisasi, rasa keadilan, dan rekan kerja akan berkontribusi meningkatkan kepuasan kerja (Chandra, 2017). Dari uraian tersebut, maka hipotesis kesatu (H1) dirumuskan sebagai berikut:

\section{H1: Perceived organizational support berpengaruh negatif terhadap turnover intent- ion.}

\section{Perceived Organizational Support (POS) dan Job Satisfaction}

Tantangan di tempat kerja ditandai dengan perubahan organisasi yang terus berkembang menyesuaikan persaingan dan memerlukan adaptasi di lingkungan sekitarnya (Cullen et al., 2014). Perubahan tidak hanya terjadi pada organisasi, tetapi perubahan juga diperlukan pada anggota organisasi, yaitu persepsi anggota dalam bersikap dan mencapai kinerja. Sikap dan kinerja yang baik pada setiap karyawan merupakan cerminan kepuasan anggota organisasi di tempat kerja (Claudia, 2018). POS juga menerapkan norma timbal balik, yaitu tingkat POS yang tinggi dapat memicu munculnya perasaan "kewajiban" berkinerja baik di dalam diri para karyawan. Dengan kata lain, persepsi karyawan menyatakan bahwa mereka akan memberikan kontribusi bagi organisasi untuk dihargai dan dijamin kesejahteraannya. Kontribusi tersebut menghasilkan sikap yang disukai. Komitmen dan kepuasan kerja dapat diterjemahkan ke dalam perilaku dan tindakan yang menguntungkan, seperti kinerja tingkat tinggi (Bano et al., 2017). karyawan memiliki perasaan yang terhubung dengan organisasi, maka mereka ingin mencapai tujuan organisasi dan juga ingin mempertahankannya dalam organisasi (Akhtar, Syed, Husnain, \& Naseer, 2019). Dari uraian tersebut, maka rumusan hipotesis kedua $(\mathrm{H} 2)$ adalah:

\section{H2: Perceived organizational support berpengaruh positif terhadapjob satisfaction.}




\section{Quality Culture dan Turnover Intention (TI)}

Manajer, terutama manajer puncak, memainkan peran penting di dalam menanamkan dan menyebarkan budaya dalam perilaku dan tindakan para anggota organisasinya. Budaya organisasi ditanamkan mulai dari proses penerimaan, pengembangan, sampai dengan tahap pensiun. Para anggota organisasi diarahkan untuk bekerja sesuai dengan nilai organisasi, sistem, dan prosedur dalam praktik kinerja (Den Hartog \& Verburg, 2004). Budaya organisasi dapat menanamkan nilai-nilai yang dianut karyawan untuk mendapatkan kepuasan kerja dan manajemen mengarahkan demi terciptanya motivasi bagi para anggota organisasi melalui penciptaan iklim organisasi dan pembentukan budaya kerja yang dapat mendorong mereka bekerja lebih keras dalam mencapai kinerja yang tinggi (Rismayadi \& Maemunah, 2016). Budaya kerja dengan memberikan motivasi kepada karyawan akan memberikan hasil pada kepuasan kerja karyawan. Dari uraian tersebut, maka hipotesis ketiga (H3) dirumuskan sebagai berikut:

\section{H3: Quality culture berpengaruh negatif terhadap turnover intention.}

\section{Quality Culture dan Job Satisfaction}

Pada umumnya, perilaku karyawan di dalam organisasi didasarkan pada Teori X dan Teori Y, yaitu dua persepsi yang berlawanan tentang bagaimana orang memandang perilaku manusia di tempat kerja dan kehidupan organisasi (Robbins, 2008). Dengan asumsi Teori X, peran manajemen adalah memaksa dan mengontrol karyawan (Anthony, 2017). Di sisi lain, Teori Y menyatakan bahwa bekerja secara alami dengan bermain dan istirahat, maka orang akan melatih pengarahan diri sendiri apabila mereka berkomitmen pada tujuan. Komitmen pada tujuan merupakan sebuah fungsi untuk mempertahankan karyawan (Paltu \& Brouwers, 2020). Asumsi Teori Y menekankan peran manajemen dalam mengembangkan potensi karyawan dan membantu mereka melepaskan potensi tersebut ke arah tujuan bersama. Peran-peran manajemen tersebut akan memunculkan kualitas budaya kerja yang membuat karyawan nyaman dan memiliki komitmen organisasi, sehingga mereka ber-keinginan tetap tinggal pada organisasi saat ini. Secara garis besar, pekerja yang secara efektif berdedikasi pada organisasi didorong untuk khawatir tentang kemakmuran organisasi. Mereka juga lebih condong mendukung arah strategis organisasi dan menyelesaikan masalah lingkungan kerja secara kreatif (Malik \& Noreen, 2015). Dari uraian tersebut, maka hipotesis keempat (H4) dirumuskan sebagai berikut:

\section{H4: Quality culture berpengaruh positif terhadap job satisfaction.}

\section{Job Satisfaction dan Turnover Intention (TI)}

Kepuasan kerja adalah perasaan mendapatkan prestasi yang diimplementasikan dalam pekerjaan yang dilakukan. Kepuasan kerja yang rendah berdampak negatif terhadap turnover intention (Asmara, 2017). Kepuasan kerja yang tinggi dikaitkan dengan TI yang rendah, sedangkan kepuasan kerja yang rendah akan mengarah pada turnover intention yang tinggi. Hal itu merupakan indikator terbaik yang terdapat pada niat kerja untuk bekerja (Saeed, Waseem, Sikander, \& Rizwan, 2014). Kepuasan kerja memiliki hubungan 
negatif yang signifikan dengan niat berpindah pekerjaan secara konsisten (Susanti \& Hadilah, 2019). Karyawan berpikir untuk meninggalkan pekerjaannya. Mereka sering membuat perbandingan pekerjaan mereka saat ini dengan pekerjaan orang lain dan mengevaluasi alternatif yang dapat mereka dapatkan dengan meninggalkan pekerjaan terakhir mereka. Alternatif yang menjadi pilihan dapat membuat persepsi karyawan untuk memiliki perilaku tetap tinggal atau meninggalkan organisasi saat ini (Saeed et al., 2014).

\section{H5: Job satisfaction berpengaruh negatif terhadap turnover intention.}

\section{METODE PENELITIAN}

Penelitian ini adalah penelitian kuantitatif yang menggunakan data primer dari penyebaran kuesioner dengan memanfaatkan google form yang dihimpun melalui WhatApps kepada supervisor pada tujuh bandara dan mereka menyebarkannya kepada para karyawan ATC yang termasuk kategori generasi Y. Ketujuh bandara tersebut adalah Bandara Yogyakarta International Airport (YIA) Kulon Progo Yogyakarta, Bandara Sultan Muhammad Salahudin Bima Nusa Tenggara Barat, Bandara Internasional Soekarno-Hatta Jakarta, Bandara Internasional Hang Nadim Batam, Bandara Sultan Mahmud Badaruddin II Palembang Sumatera Selatan, Bandara Internasional Ahmad Yani Semarang Jawa Tengah, dan Bandara Internasional Juanda Surabaya Jawa Timur (Tabel 1).

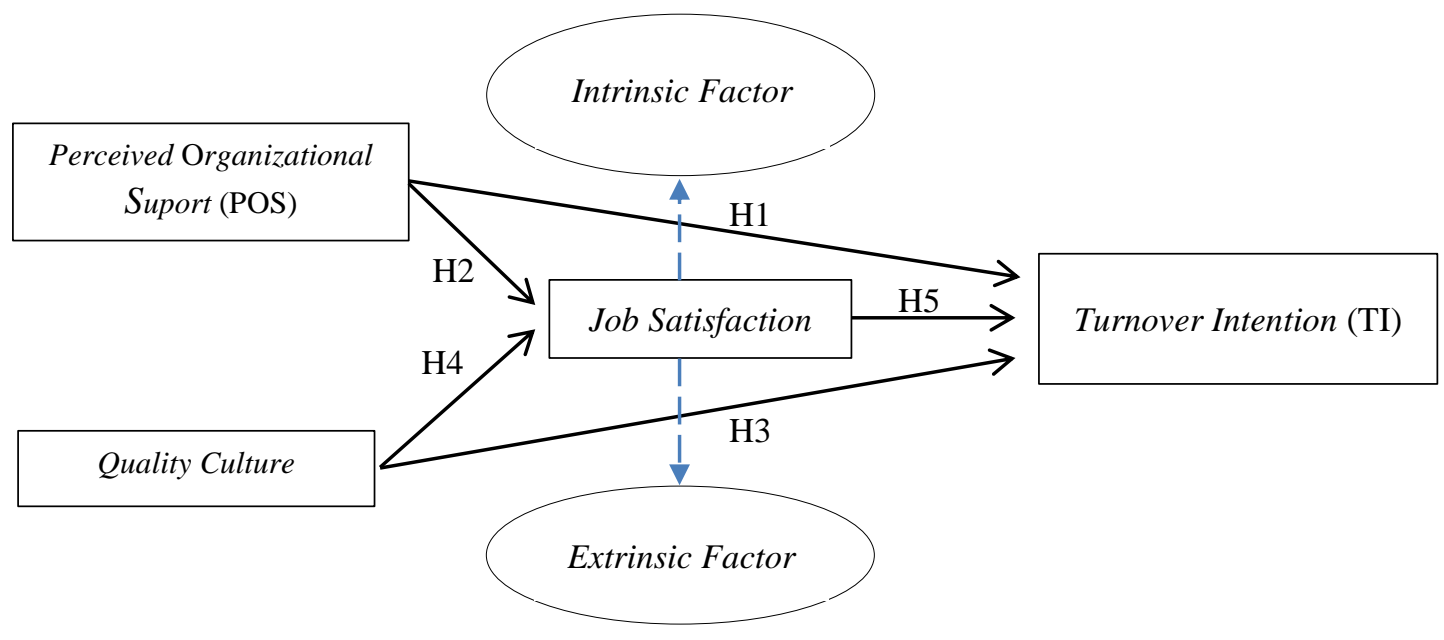

Gambar 1 Model Penelitian

Sampel penelitian ini adalah para karyawan ATC generasi Y yang berada di tujuh bandara tersebut sebanyak 300 karyawan. Kuesioner yang dikembalikan setelah diisi responden secara lengkap dan dapat diolah dalam penelitian ini sebanyak 225 kuesioner. Teknik penentuan sampel menggunakan purposive sampling, yaitu karyawan yang memiliki kategori tertentu sesuai dengan tujuan penelitian. Sampel yang dimaksud adalah kategori karyawan generasi Y yang bekerja di tujuh ATC tersebut dan berusia 36 tahun ke bawah. 
Pengukuran variabel menggunakan skala Likert dengan interval yang sama antara 1 sampai dengan 5. Pengujian hipotesis menggunakan metode structural equation modeling (SEM) sebagai alat bantu untuk menguji hubungan antarvariabel yang kompleks dan memperoleh gambaran model penelitian secara menyeluruh. Pengujian menggunakan AMOS (Analysis of Moment Structure) versi 24. Hubungan antarvariabel dalam penelitian ini ditunjukkan pada model penelitian di Gambar 1.

Tabel 2. Results of Reliability and Validity Analysis of Research

\begin{tabular}{|c|c|c|c|c|c|c|c|}
\hline \multirow[b]{2}{*}{ Construct } & \multirow[b]{2}{*}{ Dimension } & \multirow[b]{2}{*}{ Item } & \multicolumn{2}{|c|}{ KMO Barlett's } & \multirow[b]{2}{*}{ Validity } & \multirow{2}{*}{$\begin{array}{c}\text { Cronbach's } \\
\text { Alpha }\end{array}$} & \multirow[b]{2}{*}{$\begin{array}{c}\text { Loading } \\
\text { factor }\end{array}$} \\
\hline & & & $\begin{array}{c}\text { Component } \\
\text { Matrix } \\
\end{array}$ & Significant & & & \\
\hline \multirow{5}{*}{ 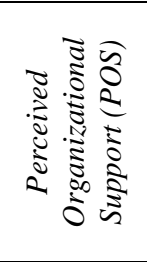 } & & $\begin{array}{l}\text { Interpersonal } \\
\text { support }\end{array}$ & 0,797 & \multirow{5}{*}{$\begin{array}{c}\text { KMO } \\
\text { Barltet's } \\
\text { coefficient }= \\
0,873 \\
\text { Sig }=0,000\end{array}$} & 0,679 & \multirow{5}{*}{0,877} & 0,725 \\
\hline & & Kerjasama & 0,832 & & 0,725 & & 0,778 \\
\hline & & Koordinasi & 0,827 & & 0,717 & & 0,787 \\
\hline & & Harmonis & 0,847 & & 0,746 & & 0,818 \\
\hline & & $\begin{array}{l}\text { Prosedur } \\
\text { keadilan }\end{array}$ & 0,792 & & 0,673 & & 0,726 \\
\hline \multirow{4}{*}{ 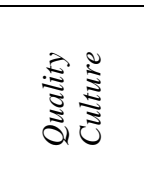 } & & Kreativitas & 0,801 & \multirow{4}{*}{$\begin{array}{c}\text { KMO } \\
\text { Barltet's } \\
\text { coefficient }= \\
0,692 \\
\operatorname{Sig}=0,000\end{array}$} & 0,637 & \multirow{4}{*}{0,805} & 0,703 \\
\hline & & $\begin{array}{l}\text { Meningkatkan } \\
\text { diri }\end{array}$ & 0,791 & & 0,622 & & 0,691 \\
\hline & & Berbagi ilmu & 0,775 & & 0,582 & & 0,707 \\
\hline & & Karier path & 0,816 & & 0,647 & & 0,759 \\
\hline \multirow{6}{*}{ 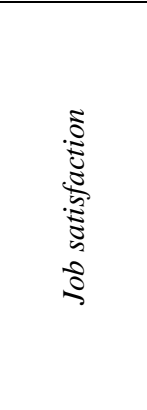 } & \multirow{3}{*}{ 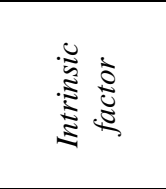 } & Help Others & 0,824 & \multirow{3}{*}{$\begin{array}{c}\text { KMO } \\
\text { Barltet's } \\
\text { coefficient }= \\
0,707 \\
\text { Sig }=0,000\end{array}$} & 0,614 & \multirow[b]{3}{*}{0,801} & 0,748 \\
\hline & & Decision & 0,858 & & 0,666 & & 0,779 \\
\hline & & $\begin{array}{l}\text { Satisfied with } \\
\text { colleagues }\end{array}$ & 0,855 & & 0,661 & & 0,712 \\
\hline & \multirow{3}{*}{ 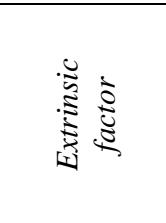 } & $\begin{array}{l}\text { Satisfied with } \\
\text { the environment }\end{array}$ & 0,845 & \multirow{3}{*}{$\begin{array}{c}\text { KMO } \\
\text { Barltet's } \\
\text { coefficient }= \\
0,707 \\
\text { Sig }=0,000\end{array}$} & 0,640 & \multirow{3}{*}{0,788} & 0,709 \\
\hline & & $\begin{array}{l}\text { Satisfied with } \\
\text { remuneration }\end{array}$ & 0,845 & & 0,639 & & 0,792 \\
\hline & & $\begin{array}{l}\text { Satisfied with } \\
\text { the supervisor }\end{array}$ & 0,829 & & 0,615 & & 0,771 \\
\hline \multirow{4}{*}{ 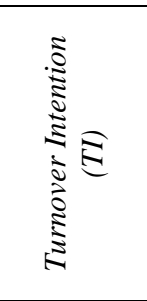 } & & $\begin{array}{l}\text { Keinginan } \\
\text { berhenti }\end{array}$ & 0,831 & \multirow{4}{*}{$\begin{array}{c}\text { KMO } \\
\text { Barltet's } \\
\text { coefficient }= \\
0,803 \\
\text { Sig }=0,000\end{array}$} & 0,680 & \multirow{4}{*}{0,832} & 0,781 \\
\hline & & $\begin{array}{l}\text { Ingin bekerja di } \\
\text { perusahaan lain }\end{array}$ & 0,787 & & 0,625 & & 0,687 \\
\hline & & $\begin{array}{l}\text { Berpindah } \\
\text { bidang lain }\end{array}$ & 0,809 & & 0,652 & & 0,725 \\
\hline & & $\begin{array}{l}\text { Berpindah pada } \\
\text { unit lain }\end{array}$ & 0,837 & & 0,692 & & 0,787 \\
\hline
\end{tabular}

Sumber: Data primer diolah (2020).

\section{HASIL DAN PEMBAHASAN}

\section{Uji Reliabilitas dan Validitas}

Pengujian keandalan skala dihitung dengan menggunakan koefisien Cronbach's alpha. Nilai-nilai koefisien alpha yang melebihi standar minimum 0,7 (Rivera, Jacomossi, Barrichello, \& Morano, 2018) memberikan perkiraan yang baik untuk keandalan konsistensi internal. Hasil uji keandalan menggunakan Kaiser Meyer Olkin (KMO) and Barlett's 
test of sphericity yang menunjukkan koefisien lebih besar dari 0,70 dikatakan signifikan (Tabel 2). Hasil ini menunjukkan bahwa skala yang digunakan dalam penelitian ini dapat diandalkan. Pengujian menggunakan confirmatory factor analysis (CFA) untuk second order pada variabel kepuasan kerja ditunjukkan pada Gambar 2.

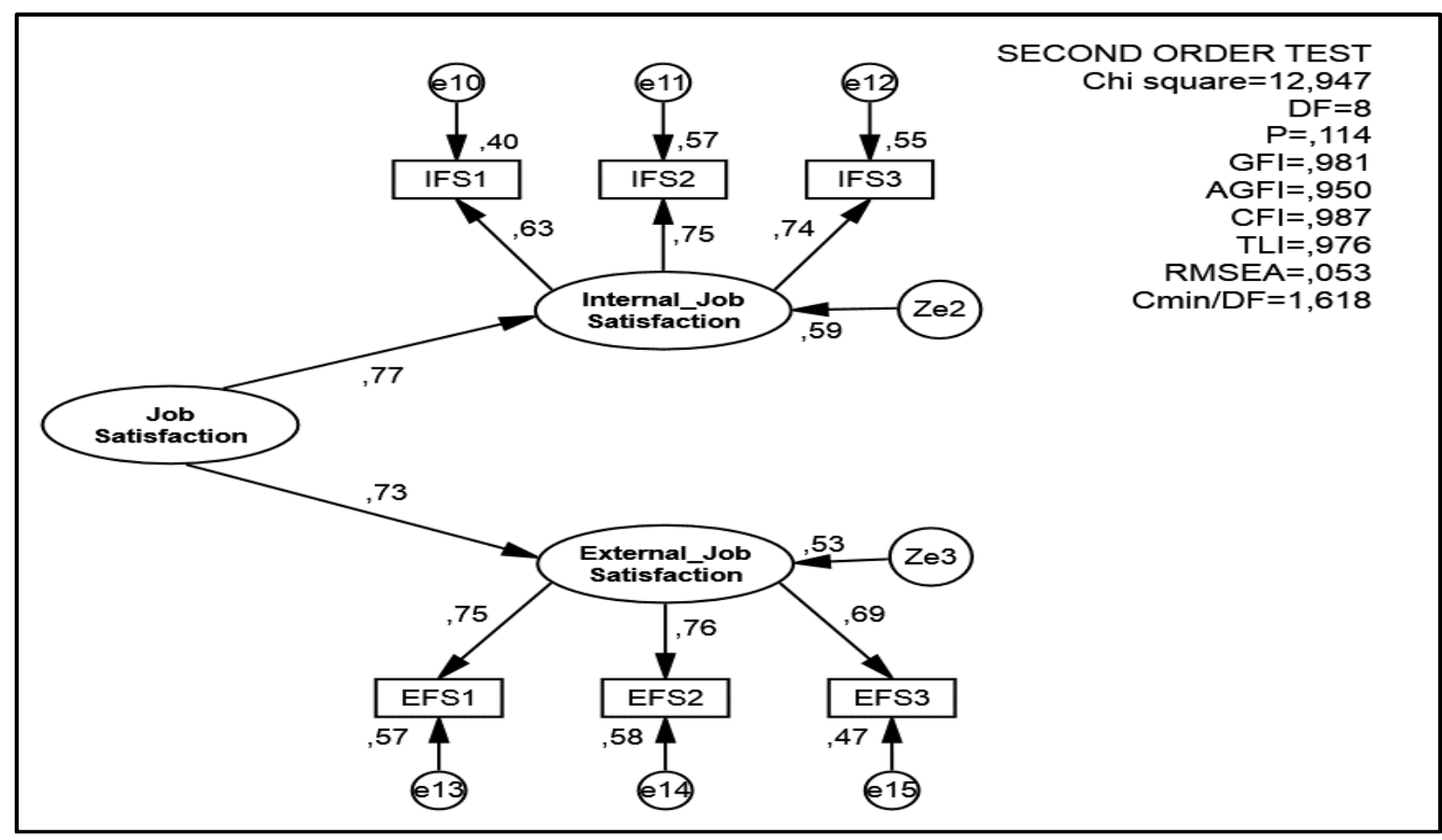

Sumber: Data primer diolah (2020).

Gambar 2. Second-order CFA pada Kepuasan Kerja

Pengujian full model SEM pada Gambar 2 menghasilkan Chi-squared ( $\left.\chi^{2}\right)$ sebesar 114 atau lebih kecil daripada 395,69 dan nilai signifikansinya (p) sebesar 0,097 atau lebih besar daripada 0,05. Rasio chi-squared dengan derajat kebebasan (df) 1,618<2; Goodnessof-fit model direpresentasikan pada root mean square error of approximation (RMSEA) sebesar 0,53 atau kurang dari 0,08. Hasil tersebut menunjukkan bahwa ada kecocokan antara model dengan data. Indeks lainnya menunjukkan goodness-of-fit $(\mathrm{GFI})=0,981$; adjust indeks goodness-of-fit $(\mathrm{AGFI})=0,950$; indeks comparative-of-fit $(\mathrm{CFI})=0,978$; dan indeks Tucker-Lewis $(\mathrm{TLI})=0,976$. Nilai-nilai tersebut menunjukkan adanya kecocokan yang memuaskan untuk model pengukuran (Hooper, Coughlan, \& Mullen, 2008). Indeks kecocokan model pengukuran dan model struktural menunjukkan bahwa model secara teoritis memiliki tingkat dukungan empiris yang memadai.

Tabel 3 menunjukkan hasil pengujian Confirmatory Factor Analysis (CFA) untuk second-order CFA pada Kepuasan Kerja. Hasil pengujian tersebut memperlihatkan bahwa Help Other (IFS1), Decision (IFS2), dan Satisfied with Colleagues (IFS3) merupakan indikator variabel yang signifikan dalam membentuk Internal Job Satisfaction. Selanjutnya, 
indikator variabel Satisfied with the Environment (EFS1), Satisfied with the Remuneration (EFS2), dan Satisfied with the Supervisor (EFS3) merupakan indikator variabel yang signifikan dalam membentuk External Job Satisfaction. Hasil tersebut ditunjukkan oleh nilai p-value masing-masing indikator yang lebih kecil daripada taraf signifikansi $(\alpha) 0,05$. Dengan demikian, model penelitian ini dapat digunakan untuk analisis berikutnya, yaitu pengujian hipotesis yang ditunjukkan pada Gambar 3.

Tabel 3. Hasil Pengujian Confirmatory Factor Analysis (CFA) untuk Second-order CFA pada Kepuasan Kerja

\begin{tabular}{lcccccc}
\hline & & Path & Estimate & S.E. & C.R. & P \\
\hline IFS1 & $\leftarrow$ & & 0,632 & 0,169 & 7,152 & 0,000 \\
IFS2 & $\leftarrow$ & Internal Job Satisfaction & 0,753 & 0,179 & 7,155 & 0,000 \\
IFS3 & $\leftarrow$ & & 0,740 & 0,143 & 8,108 & 0,000 \\
\hline EFS1 & $\leftarrow$ & & 0,753 & 0,116 & 8,763 & 0,000 \\
EFS2 & $\leftarrow$ & External Job Satisfaction & 0,763 & 0,141 & 8,617 & 0,000 \\
EFS3 & $\leftarrow$ & & 0,688 & 0,141 & 8,715 & 0,000 \\
\hline
\end{tabular}

Sumber: Data primer diolah (2020).

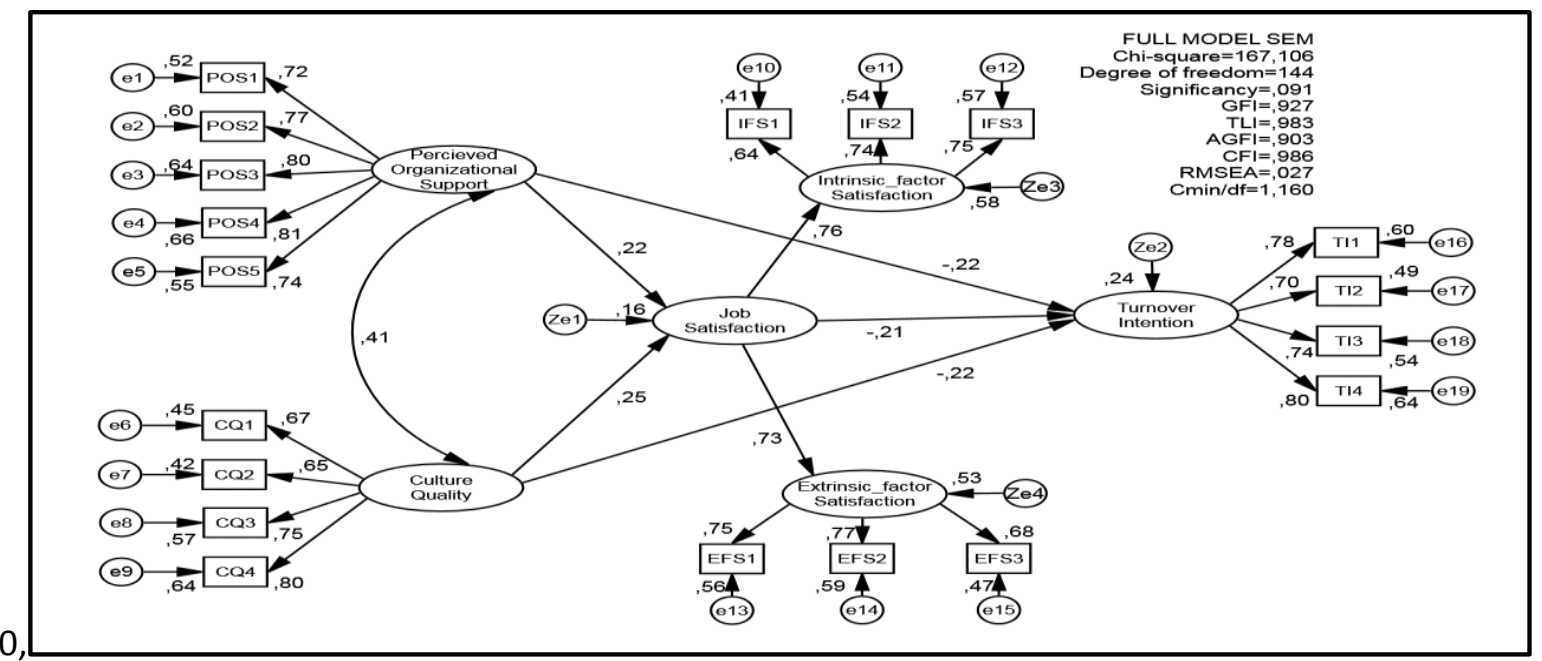

Sumber: Data primer diolah (2020).

\section{Gambar 3. Full-model SEM}

\section{Pengujian Hipotesis}

Berdasarkan hasil analisis yang ditunjukkan pada Tabel 4, pengujian hipotesis menggunakan nilai rasio kritis (CR) dan p-value dari kausalitas yang dibangun dalam kerangka pikir penelitian untuk menentukan penerimaan atau penolakan hipotesis yang diajukan. Jika p-value kurang dari 0,05, maka kausalitas dalam model penelitian disimpulkan signifikan. 
Tabel 4. Pengujian Hipotesis

\begin{tabular}{llrllllll}
\hline & $\boldsymbol{P}$ a $\boldsymbol{t} \boldsymbol{h}$ & $\begin{array}{c}\text { Std } \\
\text { Estimate }\end{array}$ & S.E. & C.R. & P & Note & Hipotesis \\
\hline POS & $\rightarrow$ & Job Satisfaction & 0,223 & 0,068 & 2,131 & 0,033 & fit & H1 diterima \\
Quality Culture & $\rightarrow$ & Job Satisfaction & 0,251 & 0,081 & 2,271 & 0,023 & fit & H2 diterima \\
Job Satisfaction & $\rightarrow$ & Turnover Intention & $-0,215$ & 0,164 & $-2,078$ & 0,038 & fit & H3 diterima \\
Quality Culture & $\rightarrow$ & Turnover Intention & $-0,218$ & 0,103 & $-2,454$ & 0,014 & fit & H4 diterima \\
POS & $\rightarrow$ & Turnover Intention & $-0,217$ & 0,088 & $-2,549$ & 0,011 & fit & H5 diterima \\
\hline
\end{tabular}

Sumber: Data primer diolah (2020).

\section{Pengaruh Perceived Organizational Support terhadap Job Satisfaction}

Pengujian hipotesis pada pengaruh Perceived Organizational Support (POS) terhadap Job Satisfaction terbukti signifikan dengan $\mathrm{CR}=2,131>\mathrm{t}$-table $=1,160$ dan $\mathrm{p}$-value $=0,033<$ 0,05. Temuan ini menjelaskan bahwa semakin baik POS, maka semakin tinggi Job Satisfaction. Pengujian ini mendukung penelitian Maslach, Schaufeli, dan Leiter (2001) yang menyatakan bahwa karyawan dengan tingkat keterikatan kerja rendah akan mengalami perasaan negatif dan tidak bahagia di tempat kerjanya, sehingga kondisi itu dapat mempengaruhi rekan kerjanya melalui emosi negatif dan cenderung mengalami kelelahan secara emosi. POS dapat membangun kepercayaan antara karyawan dengan perusahaan. Komunikasi yang terbangun dengan baik tersebut akan meningkatkan komitmen mereka kepada perusahaan. Kepuasan kerja karyawan memiliki dimensi internal job satisfaction dan external job satisfaction yang dapat meningkatkan komitmen organisasi (Coughlan, Moolman, \& Haarhoff, 2014). Variabel kepuasan kerja dapat berkontribusi pada pekerjaan secara keseluruhan, sehingga perusahaan perlu memastikan kepuasan karyawan. Kepuasan eksternal dapat membangun kepercayaan pada pemimpin yang ditunjukkan melalui dukungan supervisor. Dukungan organisasi, keadilan, dan rekan kerja dapat meningkatkan kepuasan kerja (Chandra, 2017).

Kepuasan kerja mengacu pada sikap individu terhadap karirnya. Kepuasan kerja mengacu pada kondisi emosional karyawan dan diartikan juga sebagai tanggapan efektif terhadap aspek karyawan tertentu. Seorang karyawan dengan tingkat kepuasan kerja yang tinggi akan menunjukkan sikap positif terhadap pekerjaannya. Sebaliknya, seorang pekerja yang tidak puas terhadap pekerjaannya akan menunjukkan sikap negatif terhadap karirnya (Bano et al., 2017). Penelitian ini juga sejalan dengan temuan Claudia (2018) dan Bano et al. (2017) yang menyimpulkan bahwa hubungan positif antara POS dan kepuasan kerja menunjukkan bahwa jika POS meningkat, maka kepuasan kerja juga meningkat, atau sebaliknya. Dalam penelitian ini, fasilitas yang diberikan oleh organisasi (ATC), seperti gaji, kebanggaan, dan hubungan dengan supervisor akan berpengaruh kepada keinginan karyawan untuk tetap tinggal atau meninggalkan organisasi.

\section{Pengaruh Quality Culture terhadap Job Satisfaction}

Pengujian hipotesis pada pengaruh Quality Culture terhadap Job Satisfaction terbukti signifikan dengan $\mathrm{CR}=2,271>\mathrm{t}$-table $=1,160$ dan $\mathrm{p}$-value $=0,023<0,05$. Temuan ini menjelaskan bahwa semakin baik Quality Culture, maka semakin tinggi Job Satisfaction. Hasil 
penelitian ini selaras dengan penelitian Arifin (2015), sedangkan penelitian Trivellas dan Dargenidou (2009) menunjukkan bahwa kepuasan kerja berasal dari hubungan manusia dengan pekerjaan dan lingkungan kerja. Hasil pekerjaan berhubungan positif dengan kualitas manajemen. Selain itu, kepuasan kerja berasal dari lingkungan kerja, serta hasil pekerjaan secara signifikan terkait dengan sumber daya organisasi yang diwujudkan pada dimensi kualitas layanan. Küskü (2003) berpendapat bahwa karyawan lebih produktif, ketika mereka merasa puas dengan pekerjaan dan lingkungan tempat mereka bekerja, serta berkontribusi pada peningkatan kualitas kelembagaan. Dengan demikian, kepuasan kerja dapat meningkatkan kualitas layanan. Kepuasan kerja yang dapat diwujudkan oleh organisasi kepada karyawannya akan meningkatkan layanan kepada karyawan.

\section{Pengaruh Job Satisfaction terhadap Turnover Intention}

Pengujian hipotesis atas pengaruh Job Satisfaction terhadap Turnover Intention terbukti signifikan atas dasar $\mathrm{CR}=-2,078>\mathrm{t}$-table $=1,160$ dan $\mathrm{p}$-value $=0,038<0,05$. Hasil penelitian ini menjelaskan bahwa semakin tinggi Job Satisfaction, maka semakin rendah Turnover Intention. Pengujian ini mendukung penelitian Ningsih dn Arsanti (2014), meskipun di dalam teorinya menyebutkan bahwa kepuasan kerja yang baik dapat menurunkan turnover intention. Namun, hal itu juga tergantung pada lingkungan kerja dan kondisi emosi karyawan dalam menghadapi pekerjaan dan dukungan karyawan lainnya. Menurut Mahdi, Zin, Nor, Sakat, dan Naim (2012), variabel yang menentukan turnover intention karyawan dengan pemahaman terhadap kondisi sebelumnya yang mengarah pada niat karyawan untuk berhenti dari pekerjaannya. Penghargaan pekerjaan mencerminkan manfaat intrinsik dan ekstrinsik yang diterima pekerja dari pekerjaan mereka. Penghargaan penugasan mengacu pada penghargaan intrinsik yang terkait langsung dengan melakukan pekerjaan. Imbalan organisasi yang dimaksud meliputi gaji, promosi, tunjangan, keamanan, dan kondisi kerja. Ketidakpuasan kerja banyak diidentifikasi sebagai alasan utama mengapa karyawan meninggalkan pekerjaannya. Hubungan antara kepuasan kerja dan niat untuk meninggalkan organisasi terbukti negatif (Mahdi et al., 2012). Temuan tersebut didukung penelitian Putranti et al. (2019) yang menyimpulkan bahwa kepuasan kerja atas gaji yang diterima, puas dengan pekerjaan yang ditugaskan, dan puas memiliki rekan kerja dapat menurunkan turnover intention. Hal ini sesuai dengan penelitian Ningsih dan Arsanti (2014) yang menyimpulkan bahwa kepuasan kerja berpengaruh terhadap turnover intention.

\section{Pengaruh Quality Culture terhadap Turnover Intention}

Pengujian hipotesis pada pengaruh Quality Culture terhadap Turnover Intention terbukti signifikan berdasarkan $\mathrm{CR}=-2454>\mathrm{t}$-table $=1,160$ dan $\mathrm{p}$-value $=0,014<0,05$. Studi ini menjelaskan bahwa Job Satisfaction yang semakin tinggi akan menurunkan tingkat Turnover Intention lebih rendah. Temuan ini mendukung penelitian oleh Anna, Dewi, dan Putra (2017). Budaya organisasi berpengaruh negatif terhadap turnover intention. Kecenderungan karyawan untuk keluar dari perusahaan semakin tinggi, apabila budaya organisasi tidak jelas dalam menentukan sikap, perilaku, dan pengambilan keputusan. Munculnya rasa frustrasi pada saat pengambilan keputusan akan berkaitan dengan perbedaan standar perila$\mathrm{ku}$ antara perusahaan dan keputusan yang diambil oleh karyawan, sehingga pelatihan khusus dari perusahaan perlu dilakukan untuk memahami, berinteraksi, dan mengambil keputusan sehubungan dengan situasi tersebut. Prawitasari (2016) menyatakan bahwa budaya 
kerja yang berupa peraturan perusahaan tidak menyebabkan karyawan memiliki turnover intention walaupun komunikasi dengan supervisor tidak berjalan lancar. Hal ini disimpulkan bahwa komunikasi yang baik akan memudahkan karyawan dalam mencapai kinerja seperti yang telah menjadi standar perusahaan.

\section{Pengaruh Perceived Organizational Support terhadap Turnover Intention}

Pengujian hipotesis pada pengaruh Perceived Organizational Support terhadap Turnover Intention terbukti signifikan dengan $\mathrm{CR}=-2,549>\mathrm{t}$-table $=1,011$ dan $\mathrm{p}$-value $=0,011<$ 0,05. Studi ini menjelaskan bahwa semakin tinggi Job Satisfaction, maka semakin rendah Turnover Intention. Pengujian ini mendukung penelitian (Dawley et al., 2010) yang menyimpulkan bahwa untuk tingkat yang signifikan, POS mempengaruhi turnover intention dengan memfasilitasi pemikiran tambahan bahwa seorang karyawan akan merasa dirugikan, apabila ia meninggalkan organisasi. Dengan kata lain, karyawan yang menikmati POS pada tingkat yang tinggi akan kehilangan beberapa hal seperti gaji dan tunjangan mereka, apabila ia meninggalkan perusahaan. Namun, ada juga berbagai kemungkinan sampingan, seperti partisipasi dalam pengambilan keputusan, keadilan penghargaan, otonomi, pengalaman perkembangan, keamanan kerja, dan kenyamanan lain yang ditimbulkan melalui pekerjaan dan organisasi mereka. Faktor-faktor tersebut mencerminkan kecenderungan organisasi untuk memenuhi kebutuhan sosio-emosional karyawan (Rhoades \& Eisenberger, 2002). Temuan tersebut menunjukkan bahwa POS berpengaruh secara negatif terhadap turnover intention. Temuan tersebut dapat diartikan bahwa apabila POS semakin baik, maka hal itu akan menurunkan turnover intention.

\section{KESIMPULAN DAN SARAN}

Perceived Organizational Support (POS) berpengaruh positif dan signifikan terhadap kepuasan kerja yang terdiri atas kebanggaan terhadap pekerjaan, hubungan dengan supervisor, kompensasi yang diterima, lingkungan kerja yang baik, promosi yang diberikan oleh perusahaan, dan kelompok kerja yang saling mendukung. Kepuasan intrinsik adalah karyawan yang memiliki pemikiran secara kreatif, menganggap pekerjaan tersebut penting bagi dirinya, bersedia membantu karyawan yang lain, keberlanjutan pekerjaan ini di masa mendatang, dan peluang kerja di tempat lain yang belum tentu sama dengan pekerjaan saat ini. Quality culture berpengaruh positif terhadap job satisfaction, sedangkan job satisfaction berpengaruh negatif terhadap turnover intention (TI). Quality culture berpengaruh negatif terhadap TI, sedangkan POS berpengaruh negatif terhadap TI, dan kualitas budaya kerja berpengaruh negatif terhadap turnover intention.

Dari hasil temuan ini, organisasi perlu memberikan pendampingan yang dapat dilakukan oleh supervisor di setiap kelompok kerja berupa pendekatan pertemanan dan selalu mengingatkan standart operating procedure (SOP) yang harus dipatuhi. Pendampingan diberikan kepada generasi Y melalui peran bagian sumber daya manusia. Salah satu bentuknya adalah carrier path yang transparan dapat memotivasi karyawan memiliki keinginan untuk tetap tinggal pada perusahaan saat ini. Generasi Y memiliki jenjang dan kesempatan yang terbuka untuk terus berkarir. Jika budaya kerja perusahaan dapat ditingkatkan dengan baik, hal itu akan mendorong karyawan generasi Y meningkatkan kinerjanya, sehingga gap 
generasional, gap komunikasi, flexy-time yang diinginkan, balancing working life, dan social working dapat diantisipasi dengan baik. Penelitian ini memiliki keterbatasan pada generasi Y yang bekerja pada institusi yang terafiliasi dengan pemerintah. Penelitian mendatang disarankan meneliti lebih jauh pada jenis organisasi yang berbeda dan penambahan variabel yang diteliti, seperti balancing working life dan flexy-time yang menjadi ciri khas generasi Y.

\section{DAFTAR REFERENSI}

Afsar, B., \& Badir, Y. (2017). Workplace Spirituality, Perceived Organizational Support and Innovative Work Behavior: The Mediating Effects of Person-Organization Fit. Journal of Workplace Learning, 29(2), 95-109. https://doi.org/10.1108/JWL-112015-0086.

Akhtar, M. W., Syed, F., Husnain, M., \& Naseer, S. (2019). Person-Organization Fit and Innovative Work Behavior: The Mediating Role of Perceived Organizational Support, Affective Commitment and Trust. Pakistan Journal of Commerce and Social Sciences, 13(2), 311-333.

Anna, S., Dewi, I. G. A. M., \& Putra, M. S. (2017). Pengaruh Dimensi Budaya Organisasi terhadap Turnover Intention Ekspatriat pada Hotel Bintang Lima di Nusa Dua - Bali. E-Jurnal Ekonomi dan Bisnis Universitas Udayana, 6(2), 417-444.

Antara, A. (2021). Sensus Penduduk 2020, BPS: Generasi Z dan Milenial Dominasi Jumlah Penduduk RI. Tempo.Co. Bisnis, 23 Januari 2021. https://bisnis.tempo.co/read/1425919/sensus-penduduk-2020-bps-generasi-z-danmilenial-dominasi-jumlah-penduduk-ri\#: :text=Sementara\%2C generasi milenial mencapai 69,\%2C Kamis\%2C.

Anthony, A. E. (2017). Effects of Discipline Management on Employee Performance in an Organization: The Case of County Education Office Human Resource Department, Turkana County. International Academic Journal of Human Resource and Business Administration, 2(3), 1-18.

Arifin, H. M. (2015). The Influence of Competence, Motivation, and Organisational Culture to High School Teacher Job Satisfaction and Performance. International Education Studies, 8(1), 38-45. https://doi.org/10.5539/ies.v8n1p38.

Asmara, A. P. (2017). Pengaruh Turnover Intention terhadap Kinerja Karyawan di Rumah Sakit Bedah Surabaya. Jurnal Administrasi Kesehatan Indonesia, 5(2), 123-129. https://doi.org/10.20473/jaki.v5i2.2017.123-129.

Aydogdu, S., \& Asikgil, B. (2011). An Empirical Study of the Relationship Among Job Satisfaction, Organizational Commitment and Turnover Intention. International Review of Management and Marketing, 1(3), 43-53.

Bano, S., Ramzan, S., Anjum, M. A., \& Dapeng, L. (2017). Does Perceived Social Support Mediate the Relationship of Perceived Organizational Support \& Job Satisfaction? A Structural Equation Modeling Approach. Journal of Managerial Sciences, XI(3), $105-118$. 
Budiman, J., Pujangkoro, S. A., \& Anizar, A. (2013). Analisis Beban Kerja Operator Air Traffic Control Bandara Xyz dengan Menggunakan Metode Nasa-tlx. e-Jurnal Teknik Industri PT USU, 3(3), 15-20.

Dawley, D., Houghton, J. D., \& Bucklew, N. S. (2010). Perceived Organizational Support and Turnover Intention: The Mediating Effects of Personal Sacrifice and Job Fit. The Journal of Social Psychology, 150(3), 238-257.

Chandra, C. (2017). Analisis Dampak Perceived Organizational Support terhadap Tingkat Turnover Intention. Jurnal Ilmiah Bisnis dan Ekonomi Asia, 11(1), 51-55. https://doi.org/10.32812/jibeka.v11i1.32.

Cheung, M. F. Y., \& Wu, W.-P. (2012). Leader-member Exchange and Employee Work Outcomes in Chinese Firms: The Mediating Role of Job Satisfaction. Asia Pacific Business Review, 18(1), 65-81. https://doi.org/10.1080/13602381.2010.535346.

Choong, Y.-O., Keh, C.-G., Tan, Y.-T., \& Tan, C.-E. (2013). Impacts of Demographic Antecedents toward Turnover Intention amongst Academic Staff in Malaysian Private Universities. Australian Journal of Basic and Applied Sciences, 7(6), 46-54.

Claudia, M. (2018). The Influence of Perceived Organizational Support, Job Satisfaction and Organizational Commitment toward Organizational Citizenship Behavior (A Study of the Permanent Lecturers at University of Lambung Mangkurat, Banjarmasin). Journal of Indonesian Economy and Business, 33(1), 23-45. https://doi.org/10.22146/jieb.17761.

Coughlan, L., Moolman, H., \& Haarhoff, R. (2014). External Job Satisfaction Factors Improving the Overall Job Satisfaction of Selected Five-star Hotel Employees. South African Journal of Business Management, 45(2), 97-107. https://doi.org/10.4102/sajbm.v45i2.127.

Cullen, K. L., Edwards, B. D., Casper, W. C., \& Gue, K. R. (2014). Employees' Adaptability and Perceptions of Change-Related Uncertainty: Implications for Perceived Organizational Support, Job Satisfaction, and Performance. Journal of Business and Psychology, 29(2), 269-280. https://doi.org/10.1007/s10869-013-9312-y.

da Silva, R. C., Dutra, J. S., Veloso, E. F. R., Fischer, A. L., \& Trevisan, L. N. (2015). Generational Perceptions and Their Influences on Organizational Commitment. Management Research: The Journal of the Iberoamerican Academy of Management, 13(1), 5-30.

Den Hartog, D. N., \& Verburg, R. M. (2004). High Performance Work Systems, Organisational Culture and Firm Effectiveness. Human Resource Management Journal, 14(1), 55-78. https://doi.org/10.1111/j.1748-8583.2004.tb00112.x.

Dewi, N. P. K. C., \& Dewi, A. A. S. K. (2018). Pengaruh Dukungan Organisasi dan Keadilan Imbalan terhadap Kepuasan Kerja pada Sopir Koptax Ngurah Rai Bali. EJurnal Manajemen Unud, 7(2), 1050-1079. https://doi.org/10.24843/EJMUNUD.2018.v7.i02.p18.

Direktorat Navigasi Penerbangan (2020). Laporan Data Eksisting ATC. Kementerian Perhubungan Republik Indonesia, Jakarta (Februari). 
Ehlers, U.-D. (2009). Understanding Quality Culture. Quality Assurance in Education, 17(4), 343-363. https://doi.org/10.1108/09684880910992322.

Emiroğlu, B. D., Akova, O., \& Tanrıverdi, H. (2015). The Relationship between Turnover Intention and Demographic Factors in Hotel Businesses: A Study at Five Star Hotels in Istanbul. Procedia - Social and Behavioral Sciences, 207(October), 385-397. https://doi.org/10.1016/j.sbspro.2015.10.108.

García-Morales, V. J., Lloréns-Montes, F. J., \& Verdú-Jover, A. J. (2008). The Effects of Transformational Leadership on Organizational Performance through Knowledge and Innovation. British Journal of Management, 19(4), 299-319. https://doi.org/10.1111/j.1467-8551.2007.00547.x.

Hooper, D., Coughlan, J., \& Mullen, M. R. (2008). Structural Equation Modelling: Guidelines for Determining Model Fit. Electronic Journal of Business Research Methods, 6(1), 53-60. https://doi.org/10.21427/D79B73.

Jayasundera, J. M. A., Jayakody, J. A. S. K., \& Jayawardana, A. K. L. (2017). Perceived Organizational Support and Turnover Intention of Generation Y Employees: The Role of Leader-Member Exchange. Sri Lankan Journal of Management, 21(2), 1-36.

Kam, K. J., Lim, A. S. H., Al-Obaidi, K. M., \& Lim, T. S. (2018). Evaluating Housing Needs and Preferences of Generation Y in Malaysia. Planning Practice \& Research, 33(2), 172-185. https://doi.org/10.1080/02697459.2018.1427413.

Kismono, G., Rosari, R., \& Suprihanto, J. (2013). Faktor-Faktor Demografik (Jenis Kelamin, Usia, Status Pernikahan, Dukungan Domestik) Penentu Konflik Pekerjaan dan Keluarga dan Intensi Keluar Karyawan: Studi pada Industri Perbankan Indonesia. Jurnal Siasat Bisnis, 17(2), 208-224.

Küskü, F. (2003). Employee Satisfaction in Higher Education: The Case of Academic and Administrative Staff in Turkey. Career Development International, 8(7), 347-356. https://doi.org/10.1108/13620430310505304.

Maamari, B. E., \& Saheb, A. (2018). How Organizational Culture and Leadership Style Affect Employees' Performance of Genders. International Journal of Organizational Analysis, 26(8), 1-32. https://doi.org/10.1108/IJOA-04-2017-1151.

Mahdi, A. F., Zin, M. Z. M., Nor, M. R. M., Sakat, A. A., \& Naim, A. S. A. (2012). The Relationship between Job Satisfaction and Turnover Intention. American Journal of Applied Sciences, 9(9), 1518-1526. https://doi.org/10.3844/ajassp.2012.1518.1526.

Malik, M. I., Ahmad, A., Gomez, S. F., \& Ali, M. (2011). A Study of Work Environment and Employees' Performance in Pakistan. African Journal of Business Management, 5(34), 13227-13232. https://doi.org/10.5897/ajbm11.1502.

Malik, S., \& Noreen, S. (2015). Perceived Organizational Support as a Moderator of Affective Well-being and Occupational Stress among Teachers. Pakistan Journal of Commerce and Social Sciences, 9(3), 865-874.

Martins, N., \& Martins, E. C. (2014). Perceptions of Age Generations Regarding Employee Satisfaction in a South African Organisation. Mediterranean Journal of Social Sciences, 5(21), 129-140. https://doi.org/10.5901/mjss.2014.v5n21p129. 
Maslach, C., Schaufeli, W. B., \& Leiter, M. P. (2001). Job Burnout. Annual Review of Psychology, 52, 397-422. https://doi.org/10.1146/annurev.psych.52.1.397.

McGuire, D., By, R. T., \& Hutchings, K. (2007). Towards a Model of Human Resource Solutions for Achieving Intergenerational Interaction in Organisations. Journal of European Industrial Training, 31(8), 592-608. https://doi.org/10.1108/03090590710833651.

Meier, J., Austin, S. F., \& Crocker, M. (2010). Generation Y in the Workforce: Managerial Challenges. The Journal of Human Resource and Adult Learning, 6(1), 68-78.

Ningsih, F. R., \& Arsanti, T. A. (2014). Pengaruh Job Satisfaction terhadap OCB dan Turnover Intention. Benefit: Jurnal Manajemen dan Bisnis, 18(1), 41-48. https://doi.org/10.23917/benefit.v18i1.1388.

Nurhasan, R. (2017). Kepuasan Kerja dan Loyalitas Generasi Y. Jurnal Wacana Ekonomi, 17(01), 013-023.

Paltu, A., \& Brouwers, M. (2020). Toxic Leadership: Effects on Job Satisfaction, Commitment, Turnover Intention and Organisational Culture within the South African Manufacturing Industry. SA Journal of Human Resource Management, 18(0), 1-11. https://doi.org/ 10.4102/sajhrm.v18i0.1338.

Pauli, J., Godinho-Bitencourt, R., \& Costenaro-Maciel, A. (2019). Influence of the Organizational Support on Generation Y's Work Motivation. Estudios Gerenciales, 35, 388-398. https://doi.org/10.18046/j.estger.2019.153.3266.

Prawitasari, A. (2016). Faktor-Faktor yang Mempengaruhi Turnover Intention Karyawan pada PT Mandiri Tunas Finance Bengkulu. Ekombis Review: Jurnal Ekonomi dan Bisnis, 4(2), 177-186. https://doi.org/10.37676/ekombis.v4i2.283.

Putranti, H. R. D., Lelono, J., \& Suparmi, S. (2019). Employee Turnover Intensity Analysis in Ciputra Hotel Semarang (Overview of Work Stress, Work Satisfaction and Organizational Commitment). Proceeding: International Conference on Business, Economics and Governance (ICBEG), 287-298. Semarang: FEB UNTAG (October 12).

Ratnasari, A. A., \& Prasetyo, A. R. (2018). Hubungan antara Persepsi Dukungan Organisasi dengan Stres Kerja. Jurnal Empati, 6(2), 70-76.

Retnoningsih, T., Sunuharjo, B., \& Ruhana, I. (2016). Pengaruh Kompensasi terhadap Kepuasan Kerja dan Kinerja Karyawan (Studi pada Karyawan PT PLN (Persero) Distribusi Jawa Timur Area Malang). Jurnal Administrasi Bisnis, 35(2), 53-59.

Rhoades, L., \& Eisenberger, R. (2002). Perceived Organizational Support: A Review of the Literature. Journal of Applied Psychology, 87(4), 698-714. https://doi.org/10.1037/0021-9010.87.4.698

Rismayadi, B., \& Maemunah, M. (2016). Pengaruh Motivasi Kerja, Kepemimpinan dan Budaya Organisasi terhadap Kepuasan Kerja Karyawan serta Dampaknya pada Kinerja Perusahaan (Studi Kasus pada PT Concord Indonesia). Jurnal Manajemen \& Bisnis Kreatif, 2(1), 133-157. https://doi.org/10.36805/manajemen.v2i1.181.

Rivera, J. R. D., Jacomossi, R. R., Barrichello, A., \& Morano, R. S. (2018). Using Structural Equation Modeling: Patterns and Trends of Publications in Brazilian Journals. Revista de Gestão, 25(3), 291-302. https://doi.org/10.1108/rege-05-2018-036. 
Robbins, P. S. (2008). Organizational Behaviour (Tenth edition). Jakarta: Salemba Empat.

Saeed, I., Waseem, M., Sikander, S., \& Rizwan, M. (2014). The Relationship of Turnover Intention with Job Satisfaction, Job Performance, Leader-Member Exchange, Emotional Intelligence and Organizational Commitment. International Journal of Learning \& Development, 4(2), 242-256. https://doi.org/10.5296/ijld.v4i2.6100.

Skelton, A. R., Nattress, D., \& Dwyer, R. J. (2020). Predicting Manufacturing Employee Turnover Intentions. Journal of Economics, Finance and Administrative Science, 25(49), 101-117. https://doi.org/10.1108/JEFAS-07-2018-0069.

Susanti, D., \& Hadilah, I. (2019). Pengaruh Kepuasan Kerja terhadap Turnover Intention (Studi pada CV Rabbani Asysa). Proceeding: 10th Industrial Research Workshop and National Seminar (IRWNS). Bandung: Polban, July, 24-25, 2019.

Trivellas, P., \& Dargenidou, D. (2009). Organisational Culture, Job Satisfaction and Higher Education Service Quality: The Case of Technological Educational Institute of Larissa. The TQM Journal, 21(4), 382-399. https://doi.org/10.1108/17542730910965083. 